\title{
MEMORIA DE SÍ Y EDUCACIÓN DEL OTRO EL AUTOCONOCIMIENTO COMO FUENTE DE LA ACTIVIDAD EDUCA- TIVA EN EL PENSAMIENTO DE SANTO TOMÁS DE AQUINO
}

\author{
Enrique Martínez \\ Universidad Virtual Sanfo Tomás - «Balmesiana» (Barcelona)
}

\section{RESUMEN}

El conocimiento y la enseñanza de la verdad están profundamente arraigados en la autoconciencia, y así ha sido reconocido en numerosos momentos de la historia de la Filosofía y la Teología desde que fuera grabada en el templo de Apolo, en Delfos, la exhortación Conócete a ti mismo. En este estudio se intenta mostrar la estrecha vinculación entre la autoconciencia y el orden docente en el pensamiento de Santo Tomás de Aquino, quien no sólo destaca por su doctrina acerca del hombre sino también por su profunda pedagogía.

Palabras clave: Conocimiento, educación, autoconciencia, memoria, Tomás de Aquino.

\begin{abstract}
Knowledge and teaching of truth are deep-seated in self-conscience, and thus has been recognised in several moments in history of Philosophy and Theology, since exhortation Know yourself was engraved in Apollo's temple in Delph. This study tries to show the narrow linking between self-conscience and teaching order in Saint Thomas Aquinas' thought, who stands out no only because of his doctrine, but also because of his deep pedagogy.
\end{abstract}

Key words: Knowledge, teaching, self-conscience, memory, Thomas Aquinas.

\section{CONÓCETE A TI MISMO}

Toda la paideia griega se nutrió de la sabiduría de aquella sentencia grabada en el templo de Apolo, en Delfos: «Conócete a ti mismo». ${ }^{1}$ Desde entonces la afirmación de que el conocimiento y la enseñanza de la verdad están profundamente arraigados en la autoconciencia ha recorrido la historia del pensamiento filosófico y teológico. Así lo reconoce el Papa Juan Pablo II al inicio de su encíclica Fides et Ratio en un texto que he querido usar como pórtico de mi estudio:

1 «Pero en Delfos alcanzó la religión griega un influjo más alto como fuerza educadora y lo extendió más allá de los límites de Grecia. Las sentencias más célebres de los sabios de la tierra eran consagradas a Apolo y aparecían como un eco de la sabiduría divina. Y en la puerta del templo hallaba el que entraba, en las palabras 'conócete a ti mismo', la doctrina de la sofrosyne, la exhortación a no perder de vista los límites del hombre» (Werner Jaeger, Paideia: los ideales de la cultura griega, $2^{a}$ ed., $6^{a}$ reimpr., México, Fondo de Cultura Económica, 1983, p.165). 
Tanto en Oriente como en Occidente es posible distinguir un camino que, a lo largo de los siglos, ha llevado a la humanidad a encontrarse progresivamente con la verdad y a confrontarse con ella. Es un camino que se ha desarrollado — no podía ser de otro modo- dentro del horizonte de la autoconciencia personal: el hombre cuanto más conoce la realidad y el mundo y más se conoce a sí mismo en su unicidad, le resulta más urgente el interrogante sobre el sentido de las cosas y sobre su propia existencia. Todo lo que se presenta como objeto de nuestro conocimiento se convierte por ello en parte de nuestra vida. La exhortación Conócete a ti mismo estaba esculpida sobre el dintel del templo de Delfos, para testimoniar una verdad fundamental que debe ser asumida como la regla mínima por todo hombre deseoso de distinguirse, en medio de toda la creación, calificándose como «hombre» precisamente en cuanto «conocedor de sí mismo». ${ }^{2}$

En este camino ha habido sin duda trechos más luminosos que otros. Tengo la convicción de que el recorrido a la luz del mediodía ha sido aquél en el que se ha comprendido al hombre como imagen de la Trinidad divina, por su memoria, conocimiento y amor. Esta idea ha permitido a su vez alumbrar múltiples momentos de la vida humana, entre los que me gustaría destacar la actividad educativa; trataré por ello de mostrar en este estudio la estrecha vinculación entre la autoconciencia y el orden docente. Y pienso que Santo Tomás de Aquino, Doctor Humanitatis, ${ }^{3}$ es obligada parada en este camino, tanto por su doctrina acerca del hombre, ${ }^{4}$ como por su profunda pedagogía. ${ }^{5}$

\section{EL HOMBRE VIVE POR LA RAZÓN}

El fin de la educación humana no es otro que el expresado por Píndaro: «llegar a ser lo que somos»; ${ }^{6}$ o aún mejor, con palabras de Santo Tomás: «Ser tal como Dios nos hizo». ${ }^{7}$ Y lo propio del

\section{Juan Pablo II, Fides et Ratio 1.}

3 Cfr. Juan Pablo II, Discorso ai partecipanti al Congresso Tomista (13-IX-1980), AAS 72, 1980, 1036-1046.

4 «Tomás de Aquino es el Doctor Humanitarias en un triple sentido complementario, en virtud de su doctrina. En ésta se pueden descubrir las tres dimensiones: a lo ancho, a lo profundo y a lo alto. En la extensión abarca a todos los hombres y es apta para acoger la verdad de todas las culturas. En lo profundo penetra en las raíces de lo humano y desvela los fundamentos del ser del hombre. Hacia lo alto la humanidad del hombre encuentra su perfección en Jesucristo, hombre en plenitud e Hijo de Dios, que por nosatros los hombres y por nuestra redención bajó del cielo, y se ha hecho para todos, en cuanto hombre, camino hacia Dios, via tendenti in Deum (Summa Theologiae I, q.2, prol.). En el misterio de Cristo tiene solución el problema del hombre. Tomás así lo ha comprendido y así lo ha enseñado a toda la humanidad» (Abelardo Lobato, «La antropología de Santo Tomás y las antropologías de nuestro tiempo», en A. Lobato (dir.), El pensamiento de Santo Tomás de Aquino para el hombre de hoy, vol. I «El hombre en cuerpo y alma», Valencia, Edicep, 1994, p. 36).

5 Mi tesis doctoral, defendida en la Facultad de Filosofía de la Universidad de Barcelona el 18 de febrero de 2000, consiste precisamente en un estudio acerca de la Filosofía de la educación del Aquinate y su fundamentación en el concepto de persona (Enrique Martínez, Persona y educación en Santo Tomás de Aquino, «Col-lecció de Tesis Doctorals microfitxades, núm.3776m, Barcelona, Publicacions Universitat de Barcelona, 2000).

6 «Beaucoup de nos contemporaines connaissent l'Homme primitif, au l'Homme de l'Occident, ou l'Homme de l'ère industrielle, ou l'Homme criminel, ou l'Homme bourgeois, ou l'Homme prolétarien, mais ils se demandent ce qu'on veut dire quand on parle de l'homme [...] Avant d'être un homme civilisé -j'espère du moins l'être- et un Français élevé dans les cercles intellectuelles de Paris, je suis un homme. S'il est vrai, d'autre part, que notre premier devoir, selon le mot profond qui n'est pas de Nietzsche mais de Pindare, est de devenire ce que nous sommes, rien n'est plus important pour chacun de nous, et rien n'est plus difficile, que de devenir un homme. Ainsi la tâche principale de l'éducation est avant tout 
hombre, aquello que somos y en lo que hemos de ser educados, es lo que corresponde a su vida racional, pues «el hombre vive por la razón». ${ }^{8}$

Se puede entrever en estos textos la que es una tesis básica para la adecuada comprensión de qué sea en última instancia la vida humana - y por ende aquella actividad tan humana que es la educación-, esto es, la afirmación de que el conocer no es otra cosa que ser, participado según la medida de la esencia. Es lo que afirma de un modo sintético Cayetano, el gran comentarista de Tomás: «sentir y entender no son sino cierto ser». ${ }^{9}$ La acción educativa, vinculada esencialmente por su finalidad al conocimiento, quedará por ello integrada de raíz en la dinámica vital del ser racional, y ello hasta tal punto que, en clara emulación a Cayetano, creemos expresar de modo auténtico la Filosofía de la educación de Santo Tomás al afirmar que educar es, en cierta medida, ayudar a ser.

La vida racional alcanza su modo más pleno de ser en la felicidad, «perfección última del hombre». ${ }^{10}$ Por naturaleza toda actividad cognoscitiva - tanto sensitiva como racional- no busca sino la unión con lo conocido, presente por modo de semejanza en el sujeto cognoscente; esto requière una acción apetitiva previa, por la que el sujeto sale fuera de sí en busca del objeto ausente, descansando dicho apetito cuando se alcanza la unión en el conocer. ${ }^{11}$ Siendo la acción cognoscitiva aquélla en la que se da la posesión del objeto es necesario afirmar la primacía del conocimiento sobre el apetito - excepto en el caso de que el objeto apetecido sea superior a la naturaleza del sujeto que lo apetece, como en el caso del que ama a Dios con caridad- ${ }^{12}$ Y por ello identifica Santo Tomás la felicidad, fin último de la vida racional, con un acto cognoscitivo, en el que el apetito descansà gozoso:

d'aider au développement dynamique par lequel l'homme se forme lui-même à être un homme, autrement dit de préparer l'enfant et l'adolescent à s'instruire pensant toute sa vie» (Jacques Maritain, «Pour une Philosophie de l'Éducation», anteriormente, L'Éducation à la croisée des chemins-, en Jacques et Raïssa Maritain, Oeuvres complètes, vol.VIII, Friburgo, Éditions Universitaires - París, Éditions Saint-Paul, 1988, pp.769-770).

7 Debemus nos habere quo Deus fecit nos (Santo Tomás, In Symbolum Apostolorun c.1).

8 Homo autem ratione vivit (Santo Tomás, Summa contra gentiles III, c.122).

9 Sentire et intelligere nihil aliud est quam quoddam esse (Cayetano, De anima III, c.5). Así explica esta tesis el profesor Canals: «El conocer como tal, ni se añade al ente en su ser, ni se delimita por sí mismo y en cuanto tal al ser del que conoce. Santo Tomás de Aquino, para quien el acto del ente es el ser, esse, 'de suyo nunca perfectible ni receptivo, sino siempre perfectivo y recibido', entendía ciertamente, como advirtió Cayetano, la esencia del conocer en cuanto tal como acto y ser de este ente que es perfeccionado de tal modo por el ser, que por su ser tiene constitutivamente el ser cognoscitivon (Francisco Canals, Sobre la esencia del conocimiento, Barcelona, PPU, 1987, p.303).

10 Est enim beatitudo ultima hominis perfectio (Santo Tomás, Summa Theologiae I-II, q.3, a.2 in c).

11 Cum autem operans oporteat aliquo modo coniungi suo obiecto circa quod operatur, necesse est extrinsecam rem, quae est obiectum operationis animae, secundum duplicem rationem ad animam comparari. Uno modo, secundum quod nata est animae coniungi et in anima esse per suam similitudinem. Et quantum ad hoc, sunt duo genera potentiarum, scilicet sensitivum, respectu obiecti minus communis, quod est corpus sensibile; et intellectivum, respectu obiecti communissimi, quod est ens universale. Alio vero modo, secundum quod ipsa anima inclinatur et tendit in rem exteriorem. Et secundum hanc etiam comparationem, sunt duo genera potentiarum animae, unum quidem, scilicet appetitivum, secundum quod anima comparatur ad rem extrinsecam ut ad finem, qui est primum in intentione (Santo Tomás, Summa Theologiae I, q.78, a. 1 in c).

12 In his autem quae sunt supra hominem, nobilior est dilectio quam cognitio. Perficitur enim cognitio, secundum quod cognita sunt in cognoscente, dilectio vero, secundum quod diligens trahitur ad rem dilectam. Id autem quod est supra hominem, nobilius est in seipso quam sit in homine, quia unumquodque est in altero per modum eius in quo est. E converso autem est in his quae sunt infra hominem (Santo Tomás, Summa Theologiae I-II, q.66, a.6 ad 1). 
La esencia de la felicidad consiste en un acto del entendimiento; sin embargo, pertenece a la voluntad la delectación consiguiente a la bienaventuranza, como dice Agustín en el libro X de las Confesiones, que la bienaventuranza es el gozo de la verdad; porque el gozo mismo es la consumación de la bienaventuranza. ${ }^{13}$

Y en la medida en que en este acto cognoscitivo descansa el apetito decimos de él que es contemplativo, pues no se conoce sin más una verdad, sino que se contempla, es decir, que la verdad gusta ser conocida. ${ }^{14}$ Cuando la perfección cognoscible del ente es apetecida en su misma inteligibilidad, ya no nos referimos a ella como verdadera, ni tampoco como buena, sino como bella. Tenemos así aquel trascendental del ente por el que reconocemos en él un bien apetecfule, que no es otro que su misma cognoscibilidad... Es la belleza. ${ }^{15}$

Esto nos revela que, aunque el acto cognoscitivo sea más perfecto de suyo que el apetitivo, si no alcanza el grado de contemplativo no decimos que dé la felicidad. Se requiere, por tanto, que la voluntad apetezca la contemplación de aquel bien, que, por lo mismo, no es un bien sensible, sino un bien racional y moral. No debemos confundir entonces la contemplación sensible con la contemplación racional: aquélla no hace bueno al sujeto, sino que agrada al sentido, como al mirar un paisaje hermoso; el que contempla a instancias de un acto volitivo, mira lo que ama, y este amor - si es ordenado - le perfecciona moralmente, haciéndole feliz si, además, se une a lo amado por la contemplación. El amor entre dos personas puede dar origen a un sinfín de actos, como hacerse un regalo, ayudarse en los trabajos cotidianos, pasear juntos, etc., mas la plenitud de dicho amor se alcanza en el conocimiento que uno tiene del otro, no ya físico, sino moral, es decir, de sus pensamientos más íntimos; sus deseos, sus ilusiones... Y de ahí que la felicidad plena, que sólo puede dar el Bien infinito, consiste en la contemplación del mismo rostro de Dios, cuya Belleza sacia el corazón humano: «La bienaventuranza última y perfecta sólo puede estar en la visión de la esencia divina». ${ }^{16}$

13 Essentia beatitudinis in actu intellectus consistit, sed ad voluntatem pertinet delectatio beatitudinem consequens; secundun quod Augustinus dicit, $X$ Confess., quod beatitudo est gaudium de veritate; quia scilicet ipsum gaudium est consunmatio beatitudinis (Santo Tomás, Summa Theologiae I-II, q.3, a.4 in c).

14 «El hombre - afirma Abelardo Lobato - ha nacido para la contemplación y la vida contemplativa es su horizonte apropiado» (Abelardo Lobato, «La paideia exigida por la verdad», en AA.VV., La formazione integrale domenica$n a$, Bologna, ESD, 1996, p.289).

15 Pulchrum est idem bono, sola ratione differens. Cum enim bonum sit quod omnia appetunt, de ratione boni est quod in eo quietetur appetitus, sed ad rationem pulchri pertinet quod in eius aspectu seu cognitione quietetur appetitus [...] Et sic patet quod pulchrum addit supra bonum, quendam ordinem ad vim cognoscitivan, ita quod bonum dicatur id quod simpliciter complacet appetitui; pulchrun autem dicatur id cuius ipsa apprehensio placet (Santo Tomás, Sumna Theologiae I-II, q.27, a.1 in c).

16 Ultima et perfecta beatitudo non potest esse nisi in visione divinae essentiae (Santo Tomás, Summa Theologiae I-II, q.3, a.8 in c). Conviene recordar aquí el texto en el que Santo Tomás, comentando a Ricardo de San Víctor, describe los grados de contemplación, que culminan en «la contemplación sublime de la verdad divina, en cuya contemplación halla su perfección final» (Cfr. Santo Tomás, Summa Theologiae II-Il, q.180, a.4 ad 3). Sobre la contemplación de la esencia divina como perfección última y felicidad del hombre, véase el capítulo «Dios razón final de toda perfección» de Jaume Bofill en su obra La escala de los seres, o el dinamismo de la perfección, Barcelona, Cristiandad, 1950. 


\section{MEMORIA, INTELIGENCIA Y VOLUNTAD}

Para una mejor intelección de esta vida racional —caracterizada por el concurso del entendimiento y de la voluntad - y del orden docente derivado de ella, conviene acercarse a los textos del Aquinate en donde expone los criterios de perfección vital. ${ }^{17}$ Primero, en el capítulo 11 del libro IV de la Summa contra gentiles; allí nos habla de la diferente intimidad en lo emanado por los vivientes; y como en los seres racionales el entendimiento puede reflexionar y entenderse a sí mismo, resulta que la máxima intimidad se da en la vida racional: « $Y$ hay un grado supremo y perfecto de vida que corresponde al entendimiento, porque éste puede volver sobre sí mismo y puede entenderses. 18

Esta autoconciencia no es una cualidad añadida a la racionalidad, sino lo propio de su ser, tal y como asegura Santo Tomás cuando dice que «volver sobre su esencia no significa otra cosa sino subsistir la cosa en sí misma».${ }^{19}$ En efecto, la perfección de este ser que es el conocer se manifiesta precisamente en su subsistencia, esto es, en su independencia para existir y obrar con respecto a lo potencial que es la materia. Por eso se permite sugerir Santo Tomás la hipotética existencia de un arca subsistente, capaz de conocerse a sí misma gracias a la inmaterialidad de su ser: «Si un arca pudiese ser subsistente por sí misma sin materia, se entendería a sí misma, porque la inmunidad de la materia es la razón esencial de la intelectualidad». ${ }^{20}$

La inteligibilidad de la propia sustancia del alma - no de su acto de entender esto o aquello, ni siquiera el acto de entender aquí y ahora la propia existencia—, puede comprenderse en la línea del hábito, esto es, como disposición permanente a perfeccionarse según la propia naturaleza, una disposición permanente a entender esto o aquello y, sobre todo, a sí misma, y que es previo a la iluminación de las imágenes y a la intelección de las especies: «La mente, antes de abstraer las especies, tiene su noticia habitual, por el que puede percibirse a sí misma». ${ }^{21}$

Noticia habitual que podemos caracterizar asimismo como memoria, en terminología agustiniana, pues permite al alma recordarse siempre la misma, idéntica en el tiempo:

17 Cfr. Eudaldo Forment, Id a Tomás, Pamplona, Fundación Gratis Dạte, 1998, pp.90-109.

18 Est igitur supremus et perfectus gradus vitae qui est secundum intellectum: nam intellectus in seipsum reflectitur, et seipsun intelligere potest (Santo Tomás, Summa contra gentiles IV, c.11, n.5).

19 Redire ad essentiam suam nihil aliud est quam rem subsistere in seipsa (Santo Tomás, Summa Theologiae I, q.14, a.2 ad l).

20 Si arca esset sine materia per se subsistens, esset intelligens seipsan; quia inmmunitas a materia est ratio intellectualitatis. Et secundum hoc arca sine materia non differret ab arca intelligibili (Santo Tomás, De Spirit. Creat., q.unic., a.I ad 12).

21 Mens, antequam a phantasmatibus abstrahat, suam notitian habitualem habet, qua possit percipere se esse (Santo Tomás, De Veritate q.10, a.8 ad 1). «Si afirmamos que para esta percepción y autoconciencia no se requiere percepción sensible sino para su actual ejercicio, pero que está ya constituida como hábito con anterioridad a la recepción sensible y a la iluminación de las imágenes; y reconocemos a la vez que este hábito no es ulterior a la adquisición de especies ni requiere de suyo ejercicios de actos anteriores, sino que es esencialmente el alma intelectiva en su estructura de autopresencia consistente en la posesión del ser por modo inmaterial, habremos hallado la naturaleza intelectual, la inteligibilidad intrínseca, formalmente idéntica con aquella - en cuanto a la actualidad y la inmaterialidad constitutiva del orden de lo intelectual e inteligible-, presente en el hombre, no sólo con anterioridad a toda recepción cognoscitiva, sino haciéndolo en sí mismo capaz de aquella recepción» (Francisco Canals, Op. cit., p.474). 
Cuando se dice a la mente conócete a ti misma —explica San Agustín-, con el mismo conocimiento por el que entiende lo que se dice al decir a ti misma se conoce ya a sí misma; y no por otra cosa, sino por cuanto es presente a sí misma. ${ }^{22}$

Y no se trata aquí de la memoria sensitiva, ni siquiera de la memoria intelectiva que recuerda lo conocido y amado, sino de la memoria como autoconciencia habitual previa a la intelección de las especies — noticia - y a la volición determinada libremente - amor-; por otra parte, éstas noticia y amor - se encuentran presentes a modo de hábito en la memoria de sí: «la noticia y el amor, habitualmente tomados, pertenecen sólo a la memoria». ${ }^{23}$

Esta memoria, noticia habitual de sí, no es otra cosa que la luz connatural a la propia alma, que en su ser inmaterial es inteligible para sí —no ciertamente en su esencia, como le sucede al ángel, pero sí en su esse-:

Esto no excede el alcance de la luz inteligible que nos es connatural. Luego nada impide atribuir la acción del entendimiento agente a la luz de nuestra alma, y sobre todo cuando Aristóteles compara el entendimiento agente a la luz. ${ }^{24}$

Por ello, este hábito puede ser entendido asimismo como acto ${ }^{25}$ el mismo ser en acto del alma humana subsistente e inteligible para sí. Y es que el alma humana, antes de realizar operación alguná, y previo pues al ejercicio de sus potencias, ya es; su acto de ser, tal y como ella lo participa, la constituye en toda perfección entitativa según su naturaleza, y, cómo no, en la capacidad de hacer inteligibles todas las cosas y entenderlas. Ésta es, como es sabido, la función del entendimiento agente, que ilumina las especies impresas que le llegan por medio de la sensibilidad, ${ }^{26}$ y que en el texto anteriormente citado es identificado con claridad con «la luz de nuestra alma».

Del mismo modo, pues, que el alma es patente a sí misma gracias a su inmaterialidad, así cualquier otra realidad, sin condiciones materiales por la luz del entendimiento agente, se vuelve inteligible para el entendimiento posible, realizándose entonces en su intimidad aquella unión cognoscitiva por la que el alma se hace algo uno con lo conocido. ${ }^{27} \mathrm{EI}$ entender surge así de la memoria no como el acto de la potencia, sino como el acto del acto — «actus ex actu», del mismo

22 Sed cum dicitur menti: Cognosce te ipsam, eo ictu quo intellegit quod dictum est te ipsam, cognoscit se ipsam; nec ob aliud, quam eo quod sibi praesens (San Agustín, De Trinitate X, c.9, 12).

23 Et sic, secumdum hanc assignationem haec duo, quae sunt notitia er amor, habitualiter accepta, ad memoriam tantum pertinent (Santo Tomás, De Veritate, q.10, a.4 in c).

24 Hoc autem non excedit modum luminis intelligibilis nobis connaturalis. Unde nihil prohibet ipsi lumini nostrae animae attribuere actionem intellectus agentis: et praecipue cum Aristoteles intellectus agentem comparet lumini (Santo Tomás, Summa contra gentiles II, c.77).

25 Sed accipitur habitus secundum quod dividitur contra privationem et potentiam: sicut omnis; sicut omnis forma et actus potest dici habitus intelligibili (Santo Tomás, Summa contra gentiles II, c.78).

26 Est igitur in anima intellectiva virtus activa in phantasmata, faciens ea intelligibilia actu; et haec potentia animae vocatur intellectus agens (Santo Tomás, Summa contra gentiles II, c.77).

27 Haec est perfectio cognoscentis in quantum est cognoscens, quia secundum hoc a cognoscente aliquid cognoscitur quod ipsum cognitum est aliquo modo apud cognoscentem; et ideo in III De anima dicitur, anima esse quodammodo omnia, quia nata est omnia cognoscere [...] Perfectio autem unius rei in altero esse non potest secundum determinatum esse quod habebat in re illa; et ideo ad hoc quod nata sit esse in re altera, oportet eam considerari absque his quae nata sunt eam determinare. Et quia formae et perfectiones rerum per materiam determinantur, inde est quod secundum hoc aliqua res est cognoscibilis secundum quod a materia separatur (Santo Tomás, De Veritate c.2, a.2 in c). 
modo como el entender en acto dice en una palabra o verbo mental lo entendido. ${ }^{28}$ La autoconciencia fundamenta así el conocimiento objetivo - sin por ello olvidar que el hombre requiere hallar las especies fuera de sí, con la imprescindible mediación de la sensibilidad-.;9 Ia mente queda de este modo en su inmaterialidad abierta a un horizonte infinito de seres, los cuales es capaz de llevar a la intimidad de su conciencia en donde se hace en cierto modo todas las cosas quodammodo onmia- ${ }^{30}$

Por otro lado, en la cuestión 18 de la Prima pars de la Summa Theologiae recurre Santo Tomás a otro criterio de perfección vital, que es principio de autonomía en el obrar, según el cual es más perfecto aquel que obra por sí mismo y no es movido por otro. La verdadera autarquía, en la que el determinismo se desvanece, sólo se disfruta en la vida racional, pues en ella el fin es propuesto por uno mismo. ${ }^{31}$ No se contradicen los textos de la Summa Theologiae y de la Summa contra gentiles, sino que se complementan de modo admirable, pues es precisamente aquella intimidad en el conocer la que permite al entendimiento tener señorío sobre su propio juicio y, en consecuencia, sobre los actos libres que se derivan de él, por los que poder amar el bien conocido. ${ }^{32}$

Igual, pues, que el conocimiento objetivo, la capacidad de la voluntad para amar radica en aquella memoria o autoconciencia en donde el alma se percibe a sí misma de forma habitual. Hay en ésta, en efecto, una connatural disposición a entender y a amar, un pondus o inclinación a apetecer el bien. La palabra que surge no sólo del entendimiento, sino de la voluntad que ama, se constituye así en la palabra más perfecta, en verbum cordis o noticia amada. ${ }^{33}$ Es posible entonces el diálogo amistoso, que busca comunicar en el amor, y unir a los amigos por medio de la palabra amable. ${ }^{34}$

28 El verbo mental nace del inteligente en acto «sicut oritur actus ex actu, ut splendor ex luce» (Santo Tomás, Summa contra gentiles IV, c.14).

29 Remanet igitur ipsa anima intellectiva in potentia ad determinatas similitudines rerum cognoscibilium a nobis, quae sunt naturae rerum sensibilium. Eet has quidem determinatas naturas rerum sensibilium praesentant nobis phantasmata (Santo Tomás, Summa contra gentiles II, c.77).

30 Haec est perfectio cognoscentis in quantum est cognoscens, quia secundum hoc a cognoscente aliquid cognoscitur quod ipsum cognitum est aliquo modo apud cognoscentem; et ideo in III De anima dicitur, anima esse quodammodo omnia, quia nata est omnia cognoscere (Santo Tomás, De Veritate c.2, a.2 in c).

31 Unde supra talia animalia sunt illa quae movent seipsa, etiam habito respectu ad finem, quem sibi praestituunt. Quod quidem non fit nisi per rationem et intellectum, cuius est cognoscere proportionem finis et eius quod est ad finem, et unum ordinare in alterum. Unde perfectior modus vivendi est eorum quae habent intellectum (Santo Tomás, Summa Theologiae I, q.18, a.3 in c).

32 Tota ratio libertatis ex modo cognitionis dependet [...] Si iudicium cognitivae non sit in potestate alicuius, sed sit aliunde determinatum, nec appetitus erit in potestate eius, et per consequens nec motus vel operatio absolute. Iudicium autem est in potestate iudicantis secundum quod potest de suo iudicio iudicare: de eo enim quod est in nostra potestate, possumus iudicare. Iudicare autem de iudicio suo est solius rationis, quae super actum suum reflectitur, et cognoscit habitudines rerum de quibus iudicat, et per quas iudicat: unde totius libertatis radix est in ratione constituta (Santo Tomás, De Veritate q.24, a.2 in c). «Lo que la comparación de los dos textos muestra - afirma Canals- es que sólo la inmaterialidad plena que define la naturaleza intelectual, al abrir al viviente a un horizonte universal en la posesión de las esencias, posibilita una inclinación no determinada por la naturaleza, sino surgida desde el núcleo de su conciencia infinitamente abierta a toda la realidad» (Francisco Canals, Op. cit., p.607).

33 Cfr. San Agustín, De Trinitate IX, c.8.

34 «La relación de amistad, la que merecen las personas, es la más perfecta de todas precisamente por finalizar en la contemplación. Sólo se puede contemplar a la persona, sustancia espiritual, que se hace presente en nosotros en el ser mismo individual que posee en la realidad. Con la contemplación se realiza la 'intimidad' o 'comunión' con el amigo, se comparte una misma vida interior. Por esto, el amor de amistad busca la 'convivencia' con el amigo, su íntimo conocimiento, la compenetración» (Eudaldo Forment, Op. cit., pp. 129-130). 
El conocimiento del propio ser, la apertura a todo conocimiento verdadero y el amor por el que uno mismo quiere el bien se convierten de este modo en las claves para comprender la vida racional. Es aquella preciosa caracterización de San Agustín que define toda alma racional como mens, notitia y amor - la mente como fuente del conocimiento y del amor-; o mejor, como memoria, intelligentia y voluntas - memoria de sí mismo, inteligencia de la verdad y voluntad que ama el bien-, según el modelo de la Trinidad divina en quien la vida racional es perfecta:

Agustín señala una doble imagen de la Trinidad en la mente. La primera según estas tres cosas: la mente, la noticia y el amor, como se ve en el libro IX De Trinitate; la segunda en cuanto a estas tres que son la memoria, la inteligencia y la voluntad. ${ }^{35}$

\section{LA VIDA DOCENTE}

La vida plenamente humana hunde sus raíces en la memoria de sí, crece con el conocimiento y da fruto por el amor. Esta secuencia vital deberá estar presente, asimismo, en la dinámica de la actividad educativa; y eso es lo que trataremos de caracterizar ahora.

Toda educación nace en el corazón de un maestro, que es consciente de conocer la verdad que ama. Por eso, la exhortación conócete a ti mismo se dirige de modo particular a aquel que desea educar para que examine en su interior, a la luz de la conciencia, si es poseedor de aquella ciencia 0 virtud que pretende enseñar, y es que:

la enseñanza implica, en el docente o maestro, la perfecta acción de la ciencia; por lo que es necesario que aquel que enseña o es maestro tenga explícita y perfectamente la ciencia que causa en otro, como llega a tenerla el que aprende por la enseñanza. ${ }^{36}$

Esta ciencia perfecta del maestro queda puesta de manifiesto en la respuesta que da Tomás a la cuestión de si fue Cristo bautizado en la edad conveniente, indicando que para enseñar se requiere haber llegado al estado de virtud o edad perfecta: «Cristo se bautizó alrededor del tiempo en que comenzaba a enseñar y predicar, para lo que se requiere una edad perfecta, como son los treinta años». ${ }^{37} \mathrm{Y}$ para

35 Augustinus dupliciter assignat imaginem Trinitatus in mente. Primo secundo haec tria: mens, notitia et amor, ut patet in IX De Trinitate; secundo quantum ad haec tria, quae sunt memoria, intelligentia et voluntas (Santo Tomás, De Veritate q.10, a.4 in c). La notitia y el amor son los actos de la intelligentia y de la voluntas, respectivamente; y entendidos como hábitos pertenecen a la memoria — como antes se dijo— (cfr. Santo Tomás, Summa Theologiae I, q.93, a.7 ad 2).

36 Doctrina autem importat perfectam actionem scientiae in docente vel magistro; unde oportet quod ille qui docet vel magister est, habeat scientiam quam in altero causat, explicite et perfecte, sicut in addiscente acquiritur per doctrinam (Santo Tomás, De Veritate q.1l, a.2 in c).

37 Christus convenienter fuit in trigesimo anno baptizatus. Primo quidem, quia Christus baptizabatur quasi ex tunc incipiens docere et praedicare, ad quod requiritur perfecta aetas, qualis est triginta annortm (Santo Tomás, Summa Theologiae III, q.39, a.3 in c). La relación entre estado de virtud y edad perfecta queda clara en el siguiente texto: Tertius defectus est quod duplex est operis difficultas. Quaedam ex sola magnitudine operum; et talis difficultas, quia requirit perfectionem virtutis, non imponitur imperfectis. Quaedam vero est difficultas cohibitionis, qua magis indigent qui sunt imperfectae virtutis. Unde ptteris arctior adhibetur custodia dum sub paedagogis educantur, quam postmodum cum pervenerint ad aetatem perfectam. Status autem religionis est quaedam disciplina cohibens a peccatis, et facilius ad perfectionem inducens; sicut ex praedictis apparet. Et ideo hi qui sunt imperfectae virtutis, puta nondun in praeceptis exercitati, magis indigent tali custodia, quia facilitus est eos a peccatis abstinere tali disciplinae subiectos, quam si liberius in saeculo nutriantur (Santo Tomás, Contra doctrinam retrahentium a religione c.7). 
atender a la sapiencial exhortación del oráculo de Delfos, Santo Tomás nos propone el ejemplo de la Santísima Virgen María, cuya meditación era fructífera, íntegra y profunda. ${ }^{38}$

Esta meditación dirigida hacia el propio saber o la propia virtud hace que éstos se conviertan ante la memoria de sí como vivencia: «Todo lo que se presenta como objeto de nuestro conocimiento se convierte por ello [la autoconciencia] en parte de nuestra vida». ${ }^{39}$. Las palabras del maestro fluyen entonces de esa experiencia de vida — «manantial de vida es la boca del justo» (Prov 10, 11) -, que busca transmitirse, comunicarse, pues «de lo que rebosa el corazón habla la boca» (Mt 12,34). No es de extrañar que la educación así encuentre su lugar primordial en el seno de la familia, en cuya intimidad los padres comunican a sus hijos la propia vida por medio de palabras que éstos siempre recuerdan agradecidos: «con nuestros propios oídos lo oímos, nos lo contaron nuestros padres» $(\mathrm{Sal} 43,2)$.

Las palabras del maestro - verba doctoris - se nos revelan, pues, un momento imprescindible de toda educación del hombre, pues expresan la realidad en tanto que entendida por uno mismo; dice al respecto Santo Tomás en su De Magistro:

Las mismas palabras que dice el que enseña, o que se leen en un escrito, en orden a causar ciencia en el intelecto, obran de la misma manera que las cosas que están fuera del alma, porque de ambas el intelecto toma las intenciones inteligibles; aun cuando las palabras del que enseña son causa más próxima de la ciencia que las cosas sensibles que existen fuera del alma, en cuanto que son signos de las intenciones inteligibles. ${ }^{40}$

Si se objetara que en muchas ocasiones es más educativo el ejemplo del maestro que largos discursos, habría que decir que ello no contradice nuestra tesis. En efecto, es un hecho que el ejemplo educativo en el ámbito de la formación moral suele tener mucha mayor eficacia que el adoctrinamiento teórico; y hay una razón: puesto que el educador debe ser perfecto en aquello que desea comunicar, en la educación moral no sólo se le exigirá un conocimiento acerca de la virtud a enseñar, sino su misma presencia en el apetito; de ahí que el educando se verá más atraído hacia una virtud moral cuando la vea practicar que cuando oiga hablar de ella. Santo Tomás también se refiere a ello, dándonos precisamente como razón de esta fuerza que tiene el ejemplo el que la verdad última de las acciones está en ellas mismas:

En lo que concierne a las acciones y pasiones humanas se cree menos en las palabras que en las obras, con lo cual, si alguien pone en práctica lo que dice ser malo, más provoca con el

38 Videte circa meditationem Beatae Mariae Virginis tria. Primo quod fuit fructuosa. Qui est fructus meditationis? Dico quod meditatio clavis est memoriae multa potentis legere et audire, sed non potentis retinere nisi meditantis. Psalm. 118, 24: Super omnes docentes me intellexi, quia testimonia tua meditatio mea est. Sicut enim cibus non nutritur nisi prius masticetur, sic non poteris proficere in scientia nisi masticando ea quae audis per frequentem meditationem. Item meditatio Beatae Virginis fuit integra; quia conservavit omnia verba. De omnibus auditis debet homo meditari. Item meditatio beatae virginis fuit profunda. Aliqui solum superficialiter volunt meditari. Si non potes onmia meditare una vice, mediteris alia vice. Maria meditabat onnia verba conferens in corde suo (Santo Tomás, Sermo Jesus proficiebat).

39 Juan Pablo II, Fides et Ratio l.

40 Ipsa verba doctoris audita, vel visa in scripta, hoc modo se habent ad causandum scientiam in intellectu sicut res quae sunt extra animam, quia ex utrisque intellectus intentiones intelligibiles accipit; quanvis verba doctoris propinquius se habeant ad causandum scientiam quam sensibilia extra animam existentia, inquantum sunt signa intelligibilium intentionum (Santo Tomás, De Veritate q.11, a.1 ad 11). 
ejemplo que disuade con la palabra [...] Cuando las palabras de alguien disuenan de las obras que en él se manifiestan de una manera sensible, tales palabras dejan de ser dignas de crédito $y$, en consecuencia, viene a quedar sin valor la verdad en ellas expresada. ${ }^{41}$

Mas no significa esto que deba descuidarse el discurso acerca de qué deba o no hacerse, pues la conducta humana debe estar siempre dirigida por la razón, de manera que habrá que mostrar el fin que pretende una determinada acción propuesta como ejemplar, las circunstancias que en ella concurren, etc. Por eso afirma el Aquinate:

Las enseñanzas verbales verdaderas no sólo se muestran útiles para la ciencia, sino también para la recta conducta, pues se las cree en tanto que concuerdan con las obras; y así estas enseñanzas provocan, a los que entienden su verdad, a conformar con ellas su modo de vivir. $^{42}$

Más aún, las actitudes del maestro pertenecen al acto educativo en la medida en que hayan sido pronunciadas primero en el corazón del maestro, quien habrá deseado conseguir en otro la virtud moral —aun cuando no sepa en concreto quién será su beneficiario-.

Por eso la educación no consiste simplemente en palabras que expresan la propia vida, sino en aquellas que buscan comunicarla a otro, como ya hemos indicado anteriormente. Esto implica en el maestro el deseo de enriquecer a otro con el bien de la propia vida. Así, junto al reconocimiento del propio tesoro, el maestro descubre cerca de sí a alguien indigente de virtud, cuya pobreza mueve su corazón a desearle el bien, igual que si lo viera falto de pan, o de vestido; de ahí que asegure Santo Tomás que «el enseñar se cuenta entre las limosnas espirituales». ${ }^{43} \mathrm{Y}$ si el amor que siente hacia el indigente es fuerte, el deseo del maestro se convierte en acción educativa. Sólo por este amor la educación tiene sentido y puede ser denominada como tal —la mala educación, no es verdadera $e d u$ cación-; sólo por este amor el educador mirará con respeto al educando, tratando de conocerle, de ponderar sus capacidades, y poniendo como fin de su actividad la virtud de que adolece; sólo por este amor se esforzará por ser paciente, exigente, constante...; sólo por este amor se considerará realmente educador, perfecto en la virtud o en la ciencia que le falta a su alumno, mas humilde por la mera condición de agente secundario, que debe ir desapareciendo mientras que el discípulo crece.

Esto nos lleva a considerar ahora la persona del educando, que es la tierra en donde debe germinar la palabra del maestro. Y para que se convierta en tierra buena, debe estar abonada con el conocimiento de la propia indigencia: ¿quién que no reconozca su ignorancia, su torpeza o su inmadurez podrá sentirse ansioso de mejorar? Conócete a ti mismo, es el principio que mueve

41 Circa actiones et passiones humanas minus creditur sermonibus, quam operibus. Si enim aliquis operetur quod dicit esse malum, plus provocat exemplo quam deterreat verbo [...] Quando ergo sermones alicuius dissonant ab operibus sensibiliter in ipso apparentibus, tales sermones contemnuntur. Et per consequens interimitur verum quod per eos dicitur (Santo Tomás, In X Ethic. lect.1, n.8-9).

42 Sermones veri non solum videntur esse utiles ad scientiam, sed etiam ad bonam vitam. Creditur enim eis inquantum concordant cum operibus. Et ideo tales sermones provocant eos, qui intelligunt veritatem ipsorum ut secundum eos vivant (Santo Tomás, In X Ethic. lect.1, n.10).

43 Docere inter eleemosynas spirituales computatur (Santo Tomás, De Veritate q.11, a.4 sed con.2); por eso que afirma Piepper que «sólo el amigo» puede guiar a otro por los caminos de la virtud (Josef Pieper, Las virtudes fundamentales, trad. cast., $3^{\mathrm{a}}$ ed., Madrid, Rialp, 1990, p.67). 
también al educando y forja en él la virtud de la estudiosidad, opuesta al vicio de la curiosidad; en efecto, uno de las características del curioso es pretender lo que le supera, ${ }^{44}$ mientras que el estudioso es humilde y acepta el consejo de Tomás al hermano Juan: «No investigues las cosas que te exceden»; ${ }^{45}$ por eso el que busca la verdad sabe abrirse con docilidad a las indicaciones del maestro, y no porque vengan de él, sino porque son verdaderas; de ahí que afirme Santo Tomás que hay que saber escuchar a más de un maestro, para que «lo que no aprendas de uno, lo aprendas de otro». ${ }^{46}$

Este deseo de perfeccionarse por medio del saber o de la virtud, nacido en el reconocimiento de la propia indigencia, puede convertirse después en esperanza al encontrarse con el maestro. ${ }^{47}$ Aún no se conoce la verdad que el maestro va a enseñar, mas se confía en él, pues sus palabras o sus obras así lo testimonian. De nuevo la vida familiar se nos presenta como el lugar -útero espiritual dice Santo Tomás - ${ }^{48}$ en donde la educación revela su rostro más claro, pues es la presencia fiel de los padres la que mueve a los hijos a desear crecer como personas; por eso a la hora de definir la esencia de la educación no duda el Aquinate en situarla como fin del matrimonio:

Su fin principal [del matrimonio] es el bien de la prole: y es que no tiende la naturaleza sólo a su generación, sino también a su conducción y promoción hasta el estado perfecto del hombre en cuanto hombre, que es el estado de virtud. Por consiguiente, según el Filósofo, tres cosas nos dan los padres, que son: el ser, el alimento y la educación. ${ }^{49}$

Es esta confianza radicada en el corazón del educando la que hace fecunda su tierra, pues al escuchar la palabra de su maestro cree en ella y se deja mover por ella con docilidad:

El hombre no se hace partícipe de ese aprendizaje de repente, sino de una manera progresiva, según el modo de su naturaleza. De ahí que todo el que aprende es necesario que crea,

44 Quarto modo, inquantum aliquis studet ad cognoscendam veritatem supra proprii ingenii facultatem, quia per hoc homines de facili in errores labuntur (Santo Tomás, Summa Theologiae II-II, q.167, a.1 in c).

45 Altiora te ne quaesieris (Santo Tomás, Epistola de modo studendi). Explica al respecto el profesor Caturelli: «La estidiosidad, pues, es parte potencial de la templanza; pero también está comprehendida bajo la modestia porque el estudioso debe moderar el movimiento del espíritu hacia la propia excelencia (recuérdese que San Agustín decía de sí mismo que era nada ante Dios)» (Alberto Caturelli, «La estudiosidad y la vida espiritual», Sapientia 42, 1987, p.168).

46 Debermus audire non solum ab uno, sed a multis; quia dicit Apostolus 1 Cor. 12,4, quod divisiones gratiarum sunt. Unus non est profectus in omnibus. Beatus Gregorius optime scivit moralitates, Beatus Augustinus quaestiones solvere, et Beatus Ambrosius optime allegorizavit. Quod non addiscis ab uno, addiscis ab alio (Santo Tomás, Sermo Jesus proficiebat).

47 El encuentro personal entre el maestro y el discípulo se recuerda siempre con detalle, como aquel narrado por el evangelista: «Jesús se volvió, y al ver que le seguían les dice: ¿Qué buscáis? Ellos le respondieron: Rabí-que quiere decir, Maestro- ¿donde vives? Les respondió: Venid y lo veréis. Fueron, pues, vieron dónde vivía y se quedaron con él aquel día. Era más o menos la hora décima» (Jn 1, 38-39).

48 Filius enim naturaliter est aliquid patris. Et primo quidem a parentibus non distinguitur secundum corpus, quandiu in matris utero continetur. Postmodun vero, postquam ab utero egreditur, antequam usum liberi arbitrii habeat, continetur sub parentum cura sicut sub quodam spirituali utero (Santo Tomás, Summa Theologiae II-II, q.10, a.12 in c).

49 Alio modo dicitur naturale ad quod natura inclinat, sed mediante libero arbitrio completur, sicut actus virtutum dicuntur naturales; et hoc modo etiam matrinonium est naturale, quia ratio naturalis ad ipsum inclinat dupliciter. Primo quantum ad principalem ejus finem, qui est bonum prolis: non enim intendit natura solum generationem ejus, sed traductionem, et promotionem usque ad perfectum statum hominis, inquantum homo est, qui est virtutis status. Unde, secundum Philosophum, tria a parentibus habemus: scilicet esse, nutrimentum, et disciplinam (Santo Tomás, In IV Sent. d.26, q.1, a.1 in c). 
para así llegar a la perfección de la ciencia, como lo atestigua el Filósofo: Creer es algo necesario a quien aprende. ${ }^{50}$

Por fin, fecundada la tierra bien dispuesta del discípulo por la acción educativa de la palabra del maestro, surge como fruto otra palabra, aquella por la que el educando entiende. Tal vez aún falte mucho para hablar de virtud, pero sí se puede comenzar a hablar de educación. La semilla que ha germinado, en efecto, no es aún la planta madura, pero ya ha respondido al sembrador. La educación se convierte de este modo en un diálogo entre el maestro y su discípulo, como el que de San Agustín y su hijo Adeodato, quien comprendiendo la verdad de lo escuchado a su padre responde «verum dicis»:

Agustín.- ¿Qué te parece que pretendemos al hablar?

Adeodato.- Por lo que ahora se me alcanza, o enseñar o aprender.

Agustín.- Así lo veo yo: una de estas dos cosas, y estoy de acuerdo; pues es evidente que pretendemos enseñar cuando hablamos; mas ¿cómo aprendes?

Adeodato- ¿Cómo piensas tú?; ¿no será preguntando?

Agustin.- Entiendo que aun entonces no queremos otra cosa que enseñar. Porque dime: ¿preguntas por otra causa sino por enseñar qué es lo que quieres a aquel a quien te diriges? Adeodato- Dices la verdad.

Agustín.- Ya ves que con la locución no pretendemos otra cosa que enseñar. ${ }^{51}$

Diálogo que, por fundarse en el amor del educador al educando, y por la confianza que éste ha depositado en aquél, podemos calificar de cordial, pues es un diálogo de corazón a corazón, especialmente cuando se enseña a obrar bien. Y de este diálogo cordial no sólo se genera la virtud en el educando, que es lo que en realidad se busca, sino que además se gesta una relación entre maestro y discípulo, relación que es de agradecimiento por el bien recibido. Y se puede, incluso, ir más allá de lo que en justicia es debido al bienhechor, que es ese agradecimiento, entablándose entre maestro y discípulo una auténtica relación de amistad; ésta, aunque no sea esencial a la educación, es una preciosa corona a sus desvelos por el bien de los hombres. Así lo descubrimos en la pedagogía de Cristo, el verdadero Maestro (cfr. Mt 23,8), quien educó a sus dis̀cípulos hasta introducirlos en su amistad; y así, en el íntimo diálogo de la Última Cena, les abrió su corazón y les dio a conocer su amor con estas palabras: «No os llamo ya siervos, porque el siervo no sabe lo que hace su amo; a vosotros os he llamado amigos» (Jn 15, 15).

\author{
Enrique Martínez \\ Mallorca, 152 \\ E-08036 Barcelona
}

50 Huius autem disciplinae fit homo particeps non statim, sed successive, secundun modum suae naturae. Onmis autem talis addiscens oportet quod credat, ad hoc quod ad perfectam scientiam perveniat, sicut etiam Philosophus dicit quod oportet addiscentem credere (Santo Tomás, Summa Theologiae II-II, q.2, a.3 in c).

51 Augustinus.- Quid tibi videmur efficere velle, cum loquimur? Adeodatus.- Quantum quidem mihi nunc occurrit, aut docere aut discere. Augustinus.- Unum horum video et adsentior; nam loquendo nos docere velle manifestum est, discere autem quomodo? Adeodatus.- Quo tanden censes, nisi interroganus? Augustinus.- Etiant tunc nihil alitd quam docere nos velle intellego; nan quaero abs te, utrum ob alian causam interroges, nisi ut eum quem interrogas doceas, quid velis. Adeodatus.- Verum dicis. Augustinus.- Vides ergo iam nihil nos locutione, nisi ut doceamus adpetere? (San Agustín, De Magistro 1). 